\title{
Sustaining the development of MSEs in Indonesia: the moderating effects of the environment
}

\author{
Indah Pertiwi ${ }^{1}$ and Ruslan Prijadi ${ }^{2, *}$ \\ ${ }^{1}$ Graduate School of Management, Universitas Indonesia, Depok 16424, Indonesia. \\ ${ }^{2}$ Department of Management, Universitas Indonesia, Depok 16424, Indonesia.
}

\begin{abstract}
MSEs contribute much to the Indonesian economy and play a crucial role in achieving Sustainable Development Goals (SDGs) Unfortunately, MSEs still have limited access to finance. Financing access (SDGs' issue), support from the government (environmental aspect), and entrepreneurial traits (inside the MSEs) are central for MSEs' sustainability. This research investigates the role of a business environment built by the government to ease financial constraints and support selfefficacy in MSEs' sustainable growth. This research applies the Structural Equation Model method to 750 respondents. Initially the direct factors are estimated and then a moderating factor is added. The results find that financial constraints MSEs' experience limits the their sustainability, whereas self-efficacy enhances it. Although MSEs possess strong entrepreneurial characteristics as the basis for their growth, financing access remains a burden. The research confirms that the business environment created by the government is an effective strategy to facilitate MSEs' sustainability. However, MSEs' sustainability cannot be improved merely by government schemes but must be supported by the financial and banking sectors.
\end{abstract}

\section{Introduction}

Achieving Sustainable Development Goals (SDGs) is a global strategy to end poverty, protect the environment and provide greater wealth for all. Goal \#8 includes efforts to sustain economic growth, increase economic productivity and create decent jobs. Goal \#1 aims at the poor; most of whom are the victim of economic and political crises, loss of biodiversity and ecosystem services, natural disasters and violence.

Micro and small enterprises (MSEs) are essential elements in the effort to fight poverty and provide people decent jobs to support the economy. Sustaining MSEs growth is essential not only for them but also for the economy. MSEs create jobs for the majority of the population [1] and help reduce poverty [2]. MSEs' growth helps to achieve the SDGs of the nation [3].

\footnotetext{
${ }^{*}$ Corresponding author: ruslan.prijadi@ui.ac.id
} 
Innovation plays a central role in the survival of MSEs [4]. It precedes the MSEs' sustainability. A review of the extant literature shows that most MSEs face difficulties in innovating [5]. [6] explains that innovation can be measured using several indicators, such as improving products, services, management, and marketing. For MSEs, several barriers to innovation include financial constraints.

Haider et al. suggest that financial considerations are the heart of a MSEs' existence [7]. There are other factors that support the survivability of the MSEs such as entrepreneurial self-efficacy in the form of an individual belief to carry out the duties of entrepreneurship [8]. [9] shows several self-efficacy indicators, such as developing new products, starting a relationship and developing human capital. This research presumes that self-efficacy and financial capability are the core elements of an MSEs' internal strength.

Regardless of MSEs' internal strength, the business environment has a determining effect as well. In this case, the government plays a major role [10]. [11] shows that the government can shape the environment through policies promoting innovation. This research analyses the effects of government support as a moderator of the financial constraint and self-efficacy toward the development of innovation in MSEs. Using Structural Equation Modelling (SEM), this research examines 750 MSEs in Indonesia.

The remainder of this research report is outlined as follows. Section 2 reviews the literature and explains the hypotheses. Section 3 describes the sample and research method. The findings are discussed in Section 4. Finally, the conclusion and a recommendation are offered.

\section{Literature review and hypotheses}

The outcome of this research is that MSEs' sustainability is the result of innovation. The main questions of this research are: (a) how the MSE's internal driver (self-efficacy) and financial constraints affect the capacity for innovation and (b) how the government moderates the effects of the internal driver and financial constraints.

\subsection{Hypotheses}

\subsubsection{Financial constraints}

Internal financial constraint can be measured by the cash ratio and profitability of a firm. The higher the ratios, the easier it is for a firm to handle their financial affairs [12]. External financial constraints include the ratio of interest payment, fixed assets and liquidity ratios. These ratios indicate an MSE's accessibility to credit from a bank [13]. [14] believe the index also reflects the cost of funding and indicates financial pressures.

$\boldsymbol{H}_{\text {1. }}$ Financial constraints negatively affect the innovation of MSEs.

\subsubsection{Entrepreneurial self-efficacy}

Self-efficacy is the ability of a person to organise and carry out the necessary actions to make the accomplishment. A person with high self-efficacy has high motivation towards a task so that they can optimally function. Entrepreneurial self-efficacy is more about individual belief in oneself or the ability to succeed in achieving entrepreneurial tasks [1516]. Entrepreneurial tasks, including developing new products and market opportunities, can build an innovative environment and initiate relationships with investors. 
$\boldsymbol{H}_{2}$. Entrepreneurial self-efficacy positively supports the innovation of MSEs.

\subsubsection{Environmental supports from the government}

Environmental influences on an MSE's business operations might come in many forms but are largely regarding governmental policies. Governments can directly affect the innovation in an MSE or otherwise moderate the links between financial constraints or self-efficacy with innovation. Government supports can be benefits found in the business environment, a business platform, government-funded research, and innovation policy [17]. Governments acknowledge that innovation is the engine of growth, so they should create a favourable business environment [18].

$\boldsymbol{H}_{3 \boldsymbol{a}}$. Government supports will directly improve the innovation of MSEs.

$\boldsymbol{H}_{3 \boldsymbol{b}}$. Government supports will lessen the effects of financial constraints on the innovation of MSEs.

$\boldsymbol{H}_{3 c}$. Government supports will strengthen the effects of financial efficacy on the innovation of MSEs.

\subsection{Model and methodology}

\subsubsection{Conceptual model}

This research presumes that an MSEs' innovation is determined by internal factors (financial constraints and entrepreneurial self-efficacy) and government policies. In addition, this research applies a moderation model, i.e., a type of path analysis using moderating variables. The visualisation of the model is shown in Figure 1.

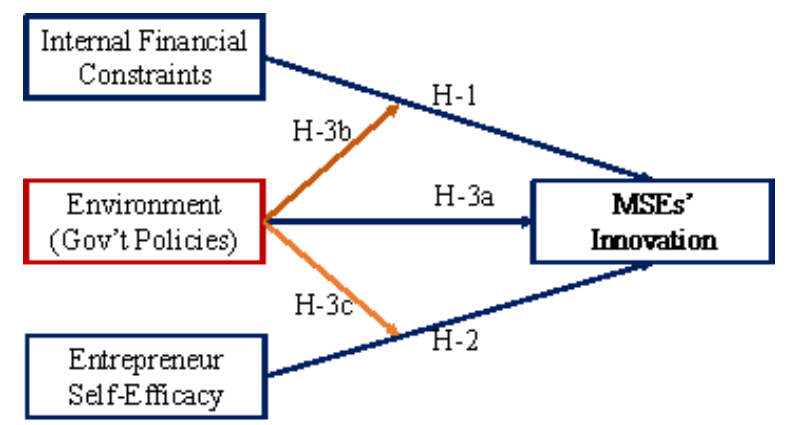

Fig 1. Conceptual model with moderating variable.

\subsubsection{The data}

Based on the Indonesian Laws No. 20/2008, the criteria for MSEs are as follows (Table 1): 
Table 1. Brief description of micro and small entreprises in Indonesia

\begin{tabular}{|l|l|l|}
\hline \multirow{2}{*}{ Category } & \multicolumn{2}{|c|}{ Criteria } \\
\cline { 2 - 3 } & \multicolumn{1}{|c|}{ Asset } & \multicolumn{1}{c|}{ Income per year } \\
\hline Micro Enterprise & Maximum Rp. 50 million & Maximum Rp. 300 million \\
\hline Small Enterprise & Rp. 50-500 million & Rp.300 million -2.5 billion \\
\hline
\end{tabular}

The data for this research are from a survey sent to 750 MSEs.

\subsubsection{Variables}

All variables used in this research are indicators measured using a Likert-type Scale (Table 2).

Table 2. Measurement of the variables.

\begin{tabular}{|l|c|c|}
\hline \multicolumn{1}{|c|}{ Latent Variable } & Indicator*) & Source \\
\hline Innovation & Likert scale (1-6) & {$[19-22]$} \\
\hline Financial Constraints & Likert scale (1-6) & {$[23-25]$} \\
\hline Self-efficacy of Entrepreneur & Likert scale (1-6) & {$[26-29]$} \\
\hline Government Supports & Likert scale (1-6) & {$[30-33]$} \\
\hline
\end{tabular}

*) The details of each indicator will be provided upon request.

\subsubsection{Estimation method}

This research uses SEM (Structural Equation Modelling) to examine the measurement model (relationship or value of loading between indicators and constructs/latent), and the structural model (the relationship between dependent and independent constructs).

\section{Results and discussion}

\subsection{Description of the Sample}

Out of 750 firms, most (91\%) of the MSEs are business owners; the remaining are family owned businesses $(5.3 \%)$ or others. Most $(90 \%)$ of the MSEs have revenue of Rp.50 million or less, the rest have revenue more than Rp.50 million. The majority (almost $88 \%$ ) of the MSEs have no bank loans when they start the business; the number is currently $74 \%$.

\subsection{Measurement model}

Before estimation using AMOS, the statistics including means, standard deviation, and internal consistency (Cronbach's alpha) are calculated. The individual values of Cronbach's alpha for all constructs are greater than 0.7 , which indicates an acceptable reliability [34]. Further, the results of the measurement model with 20 items $(\mathrm{N}=750)$ are analysed using varimax rotation and $\mathrm{KMO}$ and shows a loading factor of more than 0.5 meaning that the analysis can proceed [35]. 


\subsection{Structural model}

The structural model is estimated with the moderation effect. The results have an RMSEA (root mean square error of approximation) $=0.071$, GFI (goodness-of-fit) $=0,896$, AGFI (adjusted goodness-of-fit) $=0.869$, NFI (normed for index $)=0,927$, and CFI (comparative fit index $)=0.941$. The indices suggest that the overall causal model fits the data quite well and is good in explaining the relation among the latent variables.

Table 3 presents the direct effects and Table 4 is the model with the moderating effects.

Table 3. Direct effects of various factors on mses' innovation.

\begin{tabular}{|c|l|c|}
\hline \multicolumn{1}{|c|}{ Path } & \multicolumn{1}{c|}{ Coefficient } & t-stat \\
\hline $\mathrm{FC} \rightarrow \mathrm{INV}$ & -0.141 & $-2.888^{* * *}$ \\
\hline $\mathrm{ES} \rightarrow \mathrm{INV}$ & 0.550 & $12.738 * * *$ \\
\hline $\mathrm{DKP} \rightarrow \mathrm{INV}$ & 0.117 & $4.573 * * *$ \\
\hline
\end{tabular}

$* * *$ - significant at $\leq 0.05$.

Table 4. Moderating effects of government intervention on mses' innovation.

\begin{tabular}{|c|c|c|}
\hline Path & Coefficient & t-stat \\
\hline FC*DKP $\rightarrow$ INV & -0.334 & $-5.528^{* * *}$ \\
\hline ES*DKP $\rightarrow$ INV & 0.370 & $6.556^{* * *}$ \\
\hline
\end{tabular}

$* * *$ - significant at $\leq 0.05$.

Table 3 shows that the financial constraint has a negative and significant effect on innovation. Thus, lack of internal finance might lower MSEs' performance [36-37] and limit their growth. The internal financial difficulties limit them to get external financing and lower the chance for growth. This research also confirms that entrepreneurial self-efficacy affects innovation positively. This suggests that as long as the entrepreneurs are confident in their business, their spirit would help them to innovate and thus sustain their business.

More importantly, the results reveal many facets of environmental effects on the MSEs' capacity for innovation. The effects are proxied by government programs. First, they directly affect the MSEs' innovation capability. Second, the government effectively moderates the effects of the financial constraint and entrepreneurial self-efficacy. The government lessens the effects of internal financial weakness and heightens the effects of entrepreneurial self-efficacy among MSEs. These results are similar to those of [38-39].

\section{Conclusion}

This research clarifies the roles of the government to facilitate relationships between MSEs' financial constraints and entrepreneurial self-efficacy on their ability to innovate. First, the research indicates that there are conflicting powers inside the MSEs. On the one hand, selfefficacy would increase the MSEs' chance to grow. On the other hand, the chance might be constrained by the MSEs' financial inadequacy. Moreover, this research confirms that the environment can facilitate an MSE's sustainability through innovation. This research also highlights the moderating effects of the government. It may create a healthy environment through either lessening financial constraints or promoting self-efficacy. This implies that the government should focus their policies more on efforts to create stronger entrepreneurs 
and to ease the financing needs for MSEs (SDG's problem). Focusing on these, the government can thereby effectively provide a favourable environment to drive the MSEs' engine of innovation, which is needed for their sustainable growth.

\section{Acknowledgement}

This research is supported by Hibah PITTA 2018 funded by DRPM Universitas Indonesia.

\section{References}

1. M. Ayyagari, A. Demirguc-Kunt, V. Maksimovic, Small vs. young firms across the world (2011)

2. G.O. Essegbey, G.K. Frempong, Techn. 31, 679-688 (2011)

3. M.T.Zappia, L.Sherk. Supporting small and medium enterprises to achieve the sustainable development goals, (Blue Orchard Academy, 2017)

4. R. Hebert, A. Link, A., Jo.Tech.Trf. 31, 589-597 (2006)

5. S.X. Zeng, M.X. Xie, C.M Tam, Techn. 30, 181-194 (2010)

6. C. Lee, R. Hallak, S.R. Sardeshmukh, Tour. Mgt. 53, 215-228 (2016)

7. Z.A. Haider, M. Liu, Y. Wang, Y. Zhang, Jo. IFMIM 53, 76-93 (2018)

8. C.C. Chen, G.P. Greene, A. Crick, JBV, 13, 4, 295-316 (1998)

9. C. Lee, R. Hallak, S.R. Sardeshmukh, Tour. Mgt. 53, 215-228 (2016)

10. S. Doh, B. Kim, B. Res. Pol. 43, 1557-1569 (2014)

11. P. Patanakul, J.K. Pinto, J.K., J. Hi.Tech.Mgt 25, 97-107 (2014)

12. B. Wang, Y. Tan, M. Yu. (2015). Wrd. Econ. 12, 54-78 (2015)

13. M. Mohan, K.E. Voss, F.R. Jimenez, JBR 70, 193-201 (2017)

14. C.M. Buch, I. Kesternich, A. Lipponer, M. Schnitzer, Rev. W. Eon. 150, 393-420 (2014).

15. C.C. Chen, G.P. Greene, A. Crick, JBV, 13, 4, 295-316 (1998)

16. C. Lee, R. Hallak, S.R. Sardeshmukh, Tour. Mgt. 53, 215-228 (2016)

17. P. Patanakul, J.K. Pinto, J.K., J. Hi.Tech.Mgt 25, 97-107 (2014)

18. A.L. Goh, Int.JPSM 18, 216-240 (2005)

19. C. Lee, R. Hallak, S.R. Sardeshmukh, Tour. Mgt. 53, 215-228 (2016)

20. L. Sleuwaegen, P. Boiardi, Res. Pol. 43, 1508-1522 (2014)

21. M. Mohan, K.E. Voss, F.R. Jimenez, JBR 70, 193-201 (2017)

22. S.C. Hallenga-Brink, J.C. Brezet, J.C, Jo. Clr.Pro. 13, 141-149 (2005)

23. Y. Jin, Y., M. Luo, C. Wan, IREF 55, 54-67 (2018)

24. B. Yan, Y. Zhang, Y. Shen, Y, Ch.Ec.Rev. 47, 47-64 (2018)

25. J.Garcia-Quevedo,A.Segarra-Blasco,M.Teruel, Tech. Fcst \& Soc. Ch. 127, 127-140 (2018)

26. C. Lee, R. Hallak, S.R. Sardeshmukh, Tour. Mgt. 53, 215-228 (2016)

27. S. Barakat, M. Boddington, S. Vyakarnam, S. IJ Mgt. Edu. 12, 456-468 (2014).

28. R.S. Shinnar, D.K. Hsu, B.C. Powel, B.C., IJME 12, 561-570 (2014)

29. C.C. Chen, G.P. Greene, A. Crick, JBV, 13, 4, 295-316 (1998)

30. S. Doh, B. Kim, B. Res. Pol. 43, 1557-1569 (2014)

31. P. Patanakul, J.K. Pinto, J.K., J. Hi.Tech.Mgt 25, 97-107 (2014)

32. J. Wonglimpiyarat, J., Tech. in Soc. 33, 156-164 (2011)

33. D. Guo, Y. Guo, K. Jiang, Res. Pol. 45, 1129-1144 (2016)

34. S.X. Zeng, M.X. Xie, C.M Tam, Techn. 30, 181-194 (2010)

35. C.B. Astrachan, V.K. Patel, G. Wanzenried, JFBS, 5, 116-128 (2014). 
36. Z.A. Haider, M. Liu, Y. Wang, Y. Zhang, Jo. IFMIM 53, 76-93 (2018)

37. B. Yan, Y. Zhang, Y. Shen, Y, Ch.Ec.Rev. 47, 47-64 (2018)

38. B. Yan, Y. Zhang, Y. Shen, Y, Ch.Ec.Rev. 47, 47-64 (2018)

39. A.L. Goh, Int.JPSM 18, 216-240 (2005) 